\title{
Solid Waste Management in India Under COVID19 Pandemic: Challenges and Solutions
}

\author{
${ }^{1}$ Mohsin Anwer \\ Civil Engineering Department, \\ ZHCET AMU \\ Aligarh, India
}

\author{
${ }^{2}$ Mohd Faizan \\ Chemical Engineering Department, \\ University of Applied Sciences, \\ Münster, Germany
}

\begin{abstract}
SARS-CoV-2, most commonly known as Coronavirus, was emerged first in the Wuhan city of China in the late 2019 and proved to be an unprecedented threat to the whole world since then. It has truly imposed a restriction on human lives in many countries and has taught us a new way of living. Being the second-most populous country in the world and one of the top contenders in the hierarchy in terms of coronavirus infection, India is facing far extreme consequences of this unrestrained outbreak than many other countries in the same league. Apart from all the other challenges put forward by the existence of SARS-CoV-2, there is a need of proper management to handle the different types of solid waste especially Biomedical waste (BMW) emerging from different health care facilities, quarantine homes, and centers, that is appearing in a huge amount every day and the possible challenges we are facing while confronting the problem of this waste, that could be a source itself to spread this contagious virus, if not handled and treated properly. In this paper, we have discussed briefly the susceptibility of the virus due to Biomedical waste produced daily as a result of curing infected patients. This paper also put across the challenges and the solution to handle this waste in India before it is disposed of.
\end{abstract}

Keywords- SARS-CoV-2, Coronavirus, COVID19, Biomedical waste, color-coded

\section{INTRODUCTION}

The coronavirus disease 2019 (COVID19) has shaken the entire world lately, after coming into existence in the late 2019 in the city of Wuhan. At the time of writing this article, the total number of infections have gone over 6 million with over 3.7 lakh deaths around the globe. Currently, India is also one of the worst-hit countries in the world with over 1.8 lakh infection and over 5000 deaths [1]. The Indian data related to coronavirus shows that the peak is yet to come and India has a long way to go to control the virus. While India is fighting with coronavirus threat, there is one more aspect that needs our attention which is the biomedical waste generated from the hospitals and laboratories, for instance. Not all if it hazardous, but even the smaller amount of hazardous waste is enough to spread the virus and hinder our fight against corona.

Many researches are going on nowadays to obtain more and more information about the virus. Recent researches have shown that the virus can stay activated on plastic surfaces, cardboard, and even in the air for a varying duration. This survival property in activated form makes it even more formidable and can cause an outbreak through biomedical waste coming out from hospitals after dealing with a coronavirus patient. Hence, biomedical waste must be handled very carefully and should be treated properly in a way it does not encounter anybody in any way before it gets treated or placed in a safe place until the virus is deactivated from the waste. After the treatment, there are methods discussed in the later section which can be used to dispose of different kinds of waste. Also, various wastes need to be pretreated or disinfected before disposing of.

The problem in India is not only confined to the pretreatment or disposing of the wastes but some challenges need to be addressed to make the whole process easier and faster. The Challenges are, for example, proper segregation of the waste, which is not commonly practiced in India, knowhow of handling the waste at the staff level, proper disinfection of waste, lack of PPEs to collection staff, etc. The proper solutions to the challenges have been mentioned in the later part of this paper. These solutions are meant to mitigate the burden on our management system and to strengthen the fight against this contagious disease.

\section{NOVEL CORONA VIRUS DISEASE 2019 (NCOVID} 19) AND ITS IMPACT ON WASTE

Coronavirus belongs to the family of the Coronaviridae in the order of Nidovirales. This Coronaviridae family has a subfamily called Orthocoronavirinae which includes the alpha-coronavirus, beta coronavirus, gamma-coronavirus, and delta-coronavirus [2]. The two viruses namely SARS coronavirus (SARS-CoV) and MERS coronavirus (MERS$\mathrm{CoV}$ ) belong to the beta coronavirus family emerged in 2002 and 2012 respectively and had the deadly effects on human beings as they cross barrier among species [3][4]. The current lethal coronavirus resembles these SARS-CoV and MERS$\mathrm{CoV}$ and hence belongs to the beta family of the coronavirus. Researches have shown that this novel flu-like coronavirus is about $82 \%$ identical to the SARS-CoV and also called severe acute respiratory syndrome coronavirus 2 (SARS-CoV-2) [5][6].

The effect of this SARS-CoV-2 was first seen in the Wuhan city of China at the end of 2019 [7] and spread almost in all countries of the world and declared pandemic by World Health Organization (WHO). India has also become the victim of this deadly virus as there are 182,143 confirmed cases and 5,164 Deaths so far as on date 31 May 2020 [1] and the effect is exponentially increasing and there is no registered vaccine for the disease till date [8].

As per the epidemiological studies, there are three conditions for the spread of the virus 1) infection source 2) transmission route and 3) susceptibility [9]. The mode of the infection may be a person to person close contact, personal contacts to the infected surfaces, and the waste generated from the curing of 
the infected person. The waste generated from healthcare centers, quarantine centers, and quarantine homes is of great concern for the authorities working on impact mitigation of the COVID19. If this waste mix with general waste and handle without extra precautionary measures, then infected waste may lead to community spread of the virus and cause severe harm to human beings. Several pieces of research have been conducted on the infection spread due to waste and it has been found out that the virus can sustain on the surfaces of the material for a specific period (Table 1). The table shows the period of the virus on different surfaces [10][11]. Therefore, it is an important consideration to be taken in action in storage, collection, handling, transporting, and disposing of such waste effectively and efficiently. The virus can be cleaned with the common disinfectants used at home.

TABLE 1
\begin{tabular}{|l|l|}
\hline Surfaces & Survival Period \\
\hline Plastic & $2-3$ days \\
\hline Hard, shiny and stainless steel & $2-3$ days \\
\hline Copper & $<4$ hours \\
\hline Cardboard & $<24$ hours \\
\hline Air & $<3$ hours \\
\hline
\end{tabular}

\section{BIOMEDICAL WASTE}

Things that are not useful to the owner and have no economic value are considered as waste. The solid waste is one of the forms of waste based on the physical state. Solid waste is further be classified as the municipal, industrial, agricultural, hospital, etc. [12]. The waste generated from the hospital as a result of the curing patient (animals or human beings) and other medical and laboratory activities is termed as the Biomedical waste. The management of this waste is an integral part of controlling the infections and programs associated with hygiene in healthcare settings. The healthcare settings produce a large amount of the biomedical waste and hence is the major contributor to the infection spread through community [13]. The classification of the waste can be on the bases of the risk caused by the injury and/or in handling and disposal of the waste. The targeted waste for taking care precaution during handling and disposal includes the sharps waste (needles, blades, etc.), pathological/anatomical wastes (human tissues and fluid, placentas. Organs, etc.) and other infectious waste includes the soiled gloves, contaminated bandages or gauges (usually with blood, body fluids, viruses, or parasites). Toxic waste is also generated from the biomedical waste and this includes the pharmaceutical waste (expired drugs), chemical waste (chemical substances, disinfectants, etc.) and radioactive waste (radioactive substances, packages, glassware, urine and excreta from patients treated or tested with radionuclides and sealed sources) [14]. This is not necessary that all waste generated from hospital is hazardous whilst a large amount of the biomedical waste is non-hazardous. About $85 \%$ of waste is non- hazardous and $15 \%$ of it is hazardous waste (10\% infectious and 5\% non- infectious waste) [15].

\section{PRESENT SITUATION AND TREATMENT METHODS OF THE BIOMEDICAL WASTE IN INDIA UNDER COVID-19}

Management of solid waste is a critical and essential job in response to Coronavirus (COVID-19) pandemic. The biomedical waste from the health care institution and hospital, ward, OPD, and other departments, is generating 517 tonnes/day in India. As per the report of CPCB published in 2018, the amount of the BMW generation in 2016 is about 517 tonnes/day from $1,87,160 \mathrm{HCFs}$ whilst it was 501 tonnes/day in the year of 2015 from nearly 1,88,098 HCFs. It was studied only 501 tonnes/day waste is treated and 16 tonnes/day is remained untreated in 200 Common Biomedical Management Waste Treatment Facility (CBMWTF) in nearly 28 states. States like Goa, Andaman Nicobar, Arunachal Pradesh, Lakshadweep, Mizoram, Nagaland, and Sikkim do not have CBWTFs. The number of HCFs using CBMWTFs is 91,061, and approximately 15,281 HCFs have their treatment facilities on-site.[16] Apart from common facilities, there is 12,296 number of captive treatment and disposal facilities installed by Healthcare Facilities [17]. After spreading the novel Coronavirus disease, it was found from various sources that the amount of biomedical waste has been increased to 15 times more compared to the amount of the waste generated from the general patients. As per the report published by Biotic, the district concessionaire for biomedical waste management, about a major city 'Gurugram' said that about $10 \%$ of the total waste generated in the district comes from the curing of the COVID-19. The district currently producing 0.4 tonnes /day of COVID19 related to biomedical waste, against 0.38 tonnes/day of biomedical waste from other medical services, from approximately 36 healthcare facilities, isolation wards, testing, and quarantined centers or homes [18].There are many methods for the treatment and disposal of the various kinds of the waste in the Biomedical waste, including incineration (The controlled and complete burning of combustible (burnable) waste. Burning can be facilitated by addition of fuels, such as kerosene), autoclave (A process that achieves a specified heat and pressure to inactivate a range of infectious waste, including sharps, materials contaminated with organic materials, laboratory waste, and other patient care waste), steam-based treatment systems, irradiation methods (Irradiation methods use ultraviolet radiation or microwaves to destroy microorganisms. They supplement other disposal methods and are not easily accessible in lowand middle-income countries), Biological methods (include composting and burial, rely on the natural decomposition of organic matter. These processes are recommended for placentas), Mechanical methods (include shredding, grinding, mixing, and compacting technologies that reduce waste volumes but do not destroy microorganisms; they usually supplement other treatment methods. These processes can be used to destroy needles and syringes. Use them only after the waste has been disinfected, or as part of a closed system). sharps pit, landfills, encapsulation (a process that seals waste containers with an immobilizing material, such as cement. After hardening, the containers can be safely disposed of in landfills), ash pit, inerted (involves mixing of waste (such as pharmaceutical and high-metal-content ash) with water, lime, and cement before disposal to reduce the risk of toxic substances leaching into surface and groundwater. Pharmaceuticals must be removed from their packaging and ground before being mixed etc.) [19]

The table 2 below shows the different waste, their collection, treatment and disposal methods [20]. 


\section{CHALLENGES FACING IN INDIA}

During the COVID19 pandemic, India is facing some challenging issues which need to be addressed immediately. These challenges include 1) As the quantity of the domestic hazardous waste (DHW), also includes gloves, masks, etc., is increasing significantly, there is a problem of the collection of the waste separately. 2) No proper training is provided to staff and sanitary workers to handle the general waste, generating during COVID-19. 3) Irregular/ lack of supply of PPEs and disinfectants to the collection staff may increase the chances of them getting infected. 4) Appropriate usage and removal of the PPEs among sanitary worker, otherwise infection can be spread among workers. 5) Maintaining the social distancing as per the guidelines at collection centers as well as treatment plants. 6) Wastewater discharging from the health care facilities may have the virus, therefore operators or staff employed at the treatment plant of the wastewater may at the high risk of infection. 7) Staff associated with the sludge disposal or handling from the wastewater treatment also have chances of getting contaminated. 8) Due to lack of the door to door collecting staff from residential areas in many parts of the country, the one-point collection is prevailing there, and hence increasing the infection risk because of the residents gathering at a point. 9) Separate vehicles for collecting the COVID-19 waste from homes/quarantine centers to CBWTF and the arrangement of chemicals to disinfectant these vehicles. 10) If these vehicles are used for collecting MSW without disinfection, there is a chance of spreading the virus. 11) Towns and villages have not proper monitoring review and verification systems. 12) Waste treatment plant operators/staff are also at great risk. Regular training to the operators to handle the waste is also a challenging issue. 13) The implementation of the CPCB guidelines and SBM advisory at the ground level among the local people and other staff in waste handing. 14) The public awareness regarding the segregation of dry and wet waste and domestic hazardous waste, as per the SWM rules, cannot be provided within weeks or months. 15) At some places of the country, site conditions require the manual loading or unloading of the waste and hence increase the chances of the contaminations.

\section{SOLUTIONS}

The solutions include 1) Domestic hazardous waste (DHW) should be kept in yellow bags provided by ULBs and it should not be mixed to other general waste at the time of storing by households and collection by the collection authority. 2) The yellow bag containing the DHW should be checked properly before usage so that it cannot be leaked, and it should be away from the reach of children and pets. 3) Especially masks, gloves, and other PPEs generated from home quarantine should be kept idle in paper bags for a minimum period of 72 hours before disposal of the same as general waste or before handling to the sanitary worker. 4) A request of identifying arrangement for the collection of DHW (both wet or dry waste generated as home quarantine as SBM considers these waste as biomedical waste) to the Urban Local Bodies associated to solid waste management and this waste should not be dumped near the locality or water body or in open areas. 5)There should be a separate team to collect
COVID19 waste. 6) Only handover this waste to the authorized collector at the doorsteps, if this system of the collection exists, and if not then deposition centers for the yellow bags have been established. 7) If an alternate arrangement if available and then contact the CBMWTF operator and hand over your waste at your doorstep. 8) People generating DHW (as a result of the home quarantine) have any problem in handling the waste must contact to ULBs officials. 9) ULBs should provide the yellow bags and other facilities to the people operating Quarantine Camp and to caretakers of homecare. 10) Sanitary workers should wear PPEs and sanitize it regularly and should not touch anything (fleet/ waste buckets, even plastics, cardboard, and steel, etc.) with bare hands. 11) Doctors and other health workers should sanitize tools using for curing patients. 12) Adequate PPEs and removing procedures should also be provided for the workers in the waste processing plant. 13) People and the sanitary worker should maintain a proper distance of minimum 6 feet from the each other. 14) If anyone has got the symptoms of COVID19 then stay away from other people and work and inform the concerned people or supervisor of work. 15) The health care service provider and the sanitary worker should remove PPEs as per the protocol and wash hands, mouth, eyes, nose, etc. thoroughly. 16) Vehicles designated for collecting this waste should be regularly sanitized with sodium hypochlorite and other good disinfectants. 17) When you come out from outside should wash hands and face properly and shoes must be kept outside. 18) There should be a daily check-up before and after commissioning the work of staff working in a hospital or associated with the collective work or working in the waste processing units. 19) The monitoring and reviewing team should be constituted to monitor the collection, disposal, and even treatment of the waste. 20) The health care centers should be increased in India, especially for the COVID19. 21) An ambulate patient should try to use the attached facilities. If the patient used bedpans, use super absorbent polymer gel granules for solidification of excreta and then dispose of it as hospital waste. 22) The barcoding system for the bags containing the COVID19 waste should be properly implemented. 23) Chemical waste in the form of the liquid generated from Quarantined people should not directly be discharged into the general wastewater, there should be an appropriate treatment facility for this treatment. 24) Local govt. should strictly implement the guidelines of CPCB under COVID19. 25) Financial aid should be provided for the training of the workers and the upgradation of CBWTF treating such waste. 26) The waste generator requires that they should wash hands before putting waste containers out for collection. Sanitize or wipe handles and lids to further reduce exposure. 27) Tissues, paper towels, wipes, masks, latex gloves, or any other sanitary or cleaning materials used to protect you from the Coronavirus should NOT go into recycling carts or bins. 28) Empty, rinse, and dry your bottles, cans, and other containers before you recycle them [21][22].

\section{CONCLUSION}

It is certain that, India is not in the position to show any kind of negligence in handling and treating the waste well. There are many challenges, however with appropriate and cautious 
way of handling can mitigate the hazard. Also, proper training to the staff handling and treating might alleviate risk of further transmission of virus through this waste. The central government and the state governments need to be stricter and more attentive while considering the waste. General procedures with guidelines based on type of waste must be issued by the government and none should go without treatment following these procedures and guidelines issued by the government. Public awareness for the segregation of waste should also be promoted that might help to segregate the waste like masks and gloves which are used in homes as well to be treated before it can harm any other human beings.

\section{REFERENCES}

[1] https://www.who.int/docs/default-source/wrindia/situation-report/indiasituation-report 18.pdf?sfvrsn=7c00a3f_2

[2] Banerjee, A., Kulcsar, K., Misra, V., Frieman, M. \& Mossman, K. Bats and Coronaviruses. Viruses 11, doi:10.3390/v11010041 (2019).

[3] Schoeman, D. \& Fielding, B. C. Coronavirus envelope protein: current knowledge. Virol J 16, 69, doi:10.1186/s12985-019-1182-0 (2019).

[4] Zumla, A., Hui, D. S. \& Perlman, S. Middle East respiratory syndrome. Lancet 386, 995-1007, doi:10.1016/S0140-6736(15)60454-8 (2015)

[5] Zhang, N. et al. Recent advances in the detection of respiratory virus infection in humans. J Med Virol, doi:10.1002/jmv.25674 (2020).

[6] Chan, J. F. et al. Genomic characterization of the 2019 novel humanpathogenic coronavirus isolated from a patient with atypical pneumonia after visiting Wuhan. Emerg Microbes Infect 9, 221-236, doi:10.1080/22221751.2020.1719902 (2020).

[7] Cohen, J. \& Normile, D. New SARS-like virus in China triggers alarm. Science $367,234-235$, doi:10.1126/science.367.6475.234 (2020)

[8] Zhang, L., \& Liu, Y. (2020). Potential Interventions for Novel Coronavirus in China: A Systemic Review. Journal of Medical Virology. doi:10.1002/jmv.25707
[9] Wang, L., Wang, Y., Ye, D., \& Liu, Q. (2020). A review of the 2019 Novel Coronavirus (COVID-19) based on current evidence. International Journal of Antimicrobial Agents, 105948 doi:10.1016/j.ijantimicag.2020.105948

[10] https://www.who.int/emergencies/diseases/novel-coronavirus2019/question-and-answers-hub/q-a-detail/q-a-coronaviruses

[11] [Neeltje van Doremalen, Trenton Bushmaker, Dylan H. Morris, Myndi G. Holbrook, Amandine Gamble, Brandi N. Williamson, Azaibi Tamin, Jennifer L. Harcourt, Natalie J. Thornburg, Susan I. Gerber, James O. Lloyd-Smith, Emmie de Wit, Vincent J. Munster, "Aerosol and surface stability of HCoV-19 (SARS-CoV-6 2) compared to SARS-CoV-1", The New England Journal of Medicine.

[12] Urban Development Sector Unit, East Asia and Pacific Region, The World Bank. What a Waste: Solid Waste Management in Asia Environmental Strategies for Cities, Massachusetts Institute of Technology. [Online] 1999.

[13] B. Ramesh Babu*, A.K. Parande, R. Rajalakshmi, P. Suriyakala, M Volga, "Management of Biomedical Waste in India and Othe Countries: A Review" J. Int. Environmental Application \& Science, Vol. 4 (1): 65-78 (2009)

[14] Askarian M, Vakili M, Kabir G, (2004) Hospital waste management status in university hospitals of the Fars province, Iran. Int. J. Environ. Health Res. 14, 295-305.

[15] Glenn, Mc.R \& Garwal, R. Clinical waste in Developing Countries. An analysis with a Case Study of India, and a Critique of the Basle TWG Guidelines (1999)

[16] Central Pollution Control Board. (2018). Status on bio-medical waste management scenario and recommendations for ensuring compliance to the bio- medical waste management rules, 2016. Central Pollution Control Board (Waste Management Division-Bio-Medical Waste), Delhi-110 032 as on 13.06.2018

[17] https://www.hindustantimes.com/gurugram/covid-19-waste-accountsfor-10-of-gurugram-s-biomedical-refuse/storyZf4FZR0UuPM8MIwrlPBvdP.html

[18] https://pib.gov.in/PressReleseDetail.aspx?PRID=1602353

[19] https://openwho.org/courses/IPC-WM-EN

[20] https://ncdc.gov.in/WriteReadData/1892s/9390326671580949311.pdf

[21] https://swana.org/docs/default-source/resourcesdocuments/c19_guidelines-resident.pdf

[22] https://nidm.gov.in/covid19/PDF/covid19/research/16.pdf

TABLE 2

\begin{tabular}{|c|c|c|c|c|}
\hline $\begin{array}{l}\text { Categories } \\
\text { of the waste }\end{array}$ & Examples of the waste & $\begin{array}{l}\text { Collection bins/bags with color } \\
\text { code (non- chlorinated) }\end{array}$ & $\begin{array}{c}\text { Pretreatment } \\
\text { requirement } \\
\text { (yes/no) }\end{array}$ & Disposal options \\
\hline Soiled waste & $\begin{array}{l}\text { Items contaminated with } \\
\text { bloods, body fluids, viruses, } \\
\text { parasites, cottons swabs, } \\
\text { gauges or bandages etc. } \\
\text { (Note: - Blood is not the part } \\
\text { of this type of the waste) }\end{array}$ & $\begin{array}{l}\text { Yellow (having the thickness equal } \\
\text { to or more than } 50 \mu \text { ) }\end{array}$ & No & Incineration \\
\hline
\end{tabular}




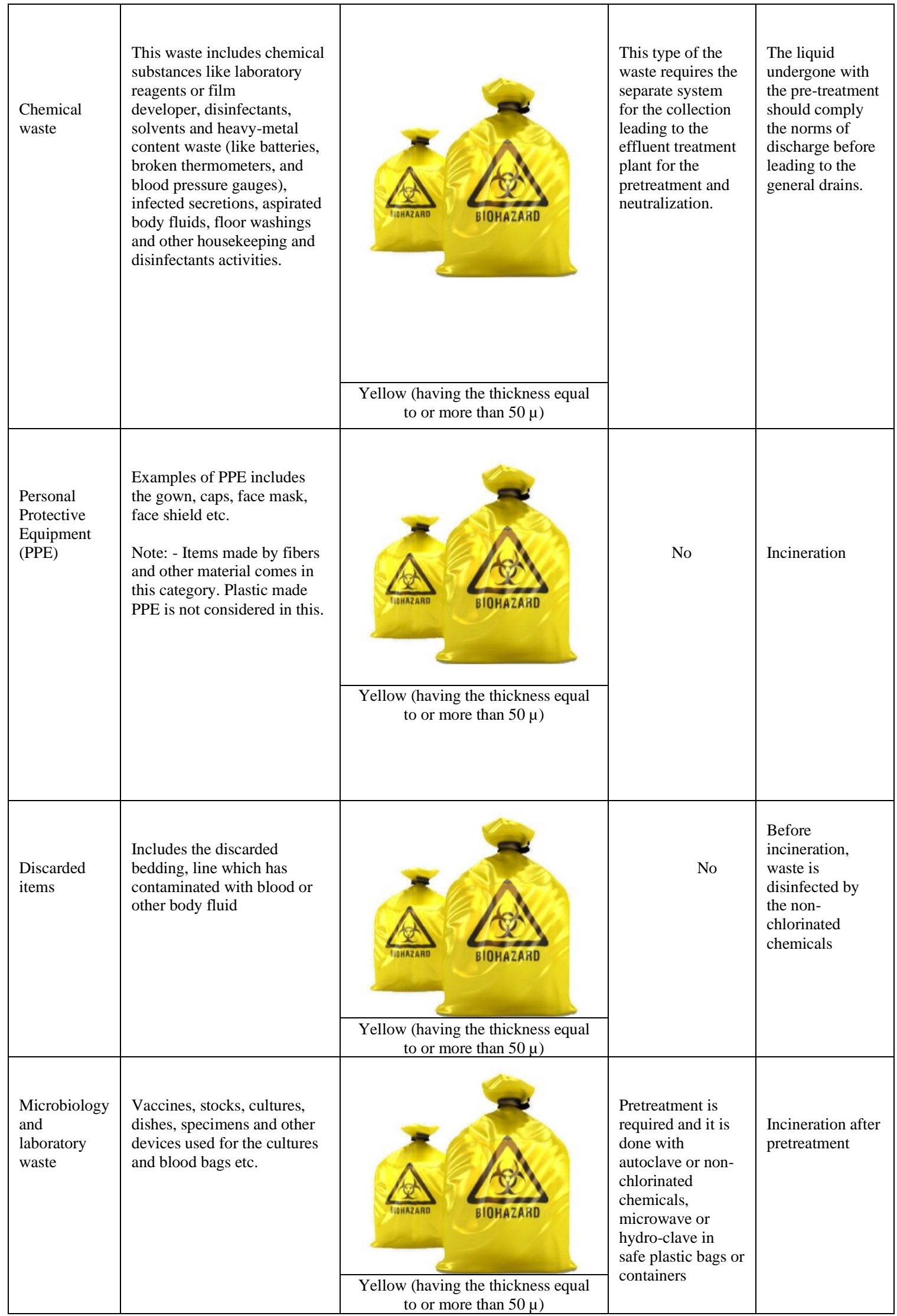




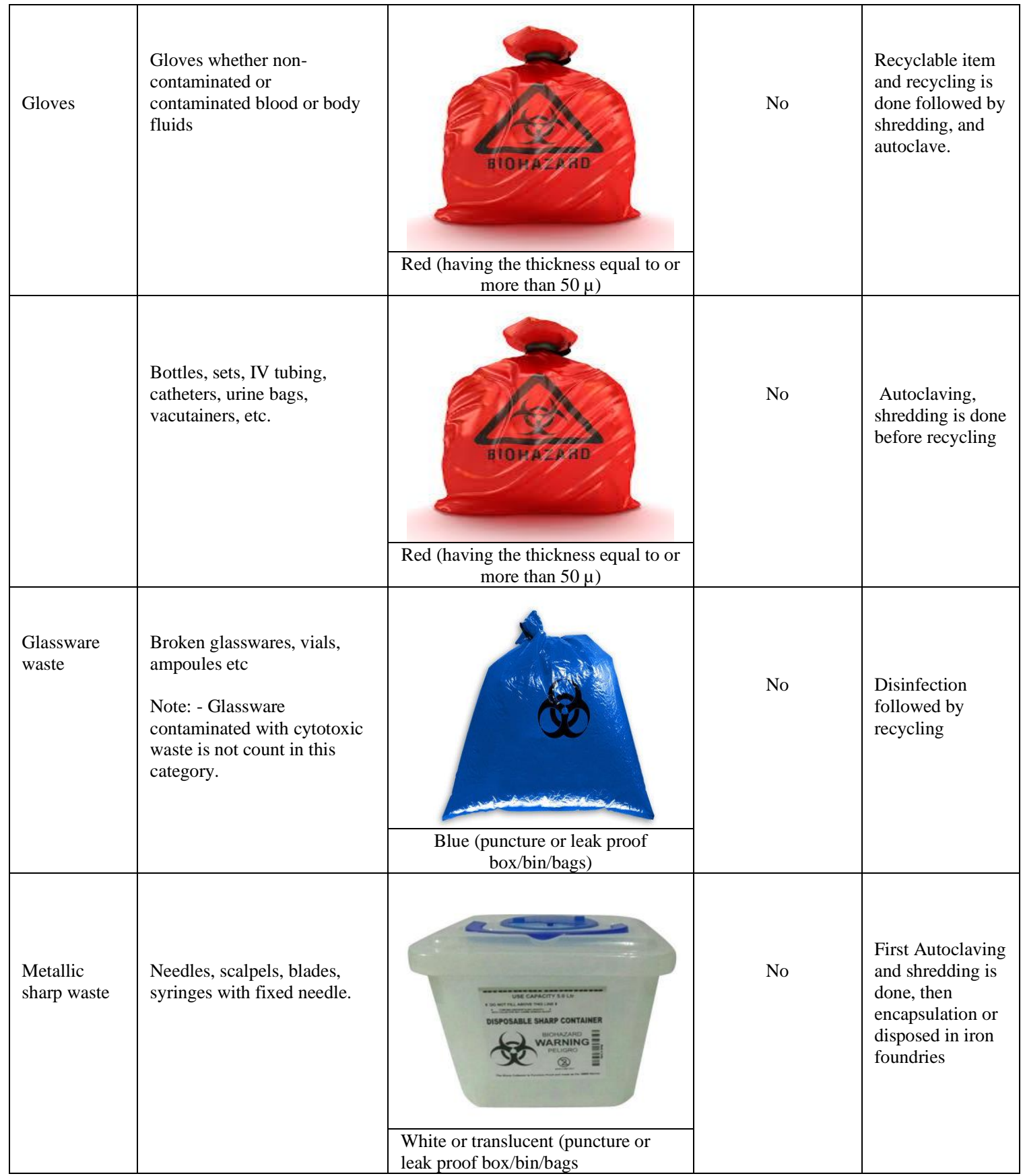

